\title{
Misdiagnosis of toxoplasma infection by PCR: fears unfounded
}

\author{
M Bhalla, J D Johnson, R E Holliman, D Savva
}

\begin{abstract}
A nested PCR based diagnostic assay for the detection of toxoplasmosis was devised in 1990 and was used successfully among a battery of tests for the clinical diagnosis of Toxoplasma gondii infection since 1991. However, it was reported that the assay produced false positive diagnoses with Nocardia asteroides infection. Investigation of this phenomenon showed that although cross reactivity with some unrelated organisms may be observed when altered conditions are employed, the assay does not lead to misdiagnosis if performed under the appropriate, stringent conditions.
\end{abstract}

(F Clin Pathol 1999;52:468-470)

Keywords: Toxoplasma gondii; polymerase chain reaction; cross reaction

Difficulties in the diagnosis of human toxoplasmosis by conventional and serological methods, especially in AIDS and organ transplant patients, led to the development of nucleic acid based diagnostic assays. Several diagnostic tests based on the polymerase chain reaction (PCR) have been devised in the last few years, with the most widely used amplifying parts of either the $\mathrm{B} 1$ gene $^{1}$ or the major surface antigen gene SAG1, ${ }^{2}{ }^{3}$ previously known as p30 gene, of Toxoplasma gondii. The assay devised in this laboratory ${ }^{2}$ is a nested PCR for the SAG1 gene in which the first amplification generates a 914 base pair (bp) fragment that is used as the target for the amplification of a 522 bp fragment in the second PCR; the PCR products may be visualised either directly on agarose gels or after Southern blotting and hybridisation. This assay has been successfully employed in conjunction with other tests to diagnose toxoplasmosis since $1991,{ }^{4}$ but a recent report ${ }^{5}$ indicated that it gives false positive results with the phylogenetically unrelated intracellular bacterium Nocardia asteroides. In preliminary studies, we investigated this cross reactivity and confirmed that it occurred with some species of Nocardia, Mycobacterium, and Actinomyces and argued that, although these organisms yield PCR products, this did not pose any problems with the diagnostic utility of the assay since sound clinical practice warrants that PCR should not be the only basis of diagnosis for toxoplasmosis. ${ }^{6}$ In this technical note we report the findings of our detailed investigations of this cross reactivity.

\section{Methods}

POLYMERASE CHAIN REACTION

Genomic DNA was isolated from the species listed in table 1 using a proteinase $\mathrm{K}$ and
Table 1 Cross reacting species and sizes of the PCR products

\begin{tabular}{|c|c|c|c|}
\hline \multirow[b]{2}{*}{ Species } & \multirow{2}{*}{$\begin{array}{l}\text { Approx size of PCR } \\
\text { products }(b p)\end{array}$} & \multicolumn{2}{|c|}{ Hybridisation at: } \\
\hline & & $60^{\circ} \mathrm{C}$ & $65^{\circ} \mathrm{C}$ \\
\hline \multicolumn{4}{|l|}{ Toxoplasma gondii } \\
\hline (RH strain) & 522 & + & + \\
\hline \multicolumn{4}{|l|}{ Nocardia spp } \\
\hline$N$ asteroides & 450 & + & - \\
\hline$N$ brasiliensis & $600,475,450,250$ & + & - \\
\hline$N$ farcinica & $750,650,425,400$ & + & - \\
\hline Notitidis-caviarum & $600,475,250$ & + & - \\
\hline \multicolumn{4}{|l|}{ Actinomyces spp } \\
\hline A naeslundii & Smear & + & - \\
\hline$A$ bovis & 100 & + & - \\
\hline A denticola & 285 & + & - \\
\hline A odontolyticus & Smear & + & - \\
\hline \multicolumn{4}{|l|}{ Mycobacterium spp } \\
\hline \multicolumn{4}{|l|}{$M$ tuberculosis } \\
\hline (7 clinical isolates) & 450 & + & - \\
\hline$M$ avium & No product & NA & NA \\
\hline Plasmodium falciparum & No product & NA & NA \\
\hline
\end{tabular}

bp, base pairs; NA, not applicable.

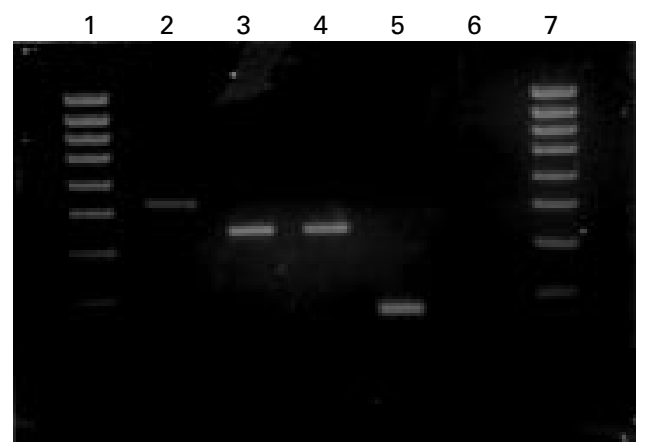

Figure 1 A representative 2\% wt/vol agarose gel showing second PCR products from Toxoplasma gondii (lane 2), Nocardia asteroides (lane 3), Mycobacterium tuberculosis (lane 4), and Actinomyces denticola (lane 5). Lane 6 is a control without DNA and lanes 1 and 7 are molecular weight markers (Gene Ruler ${ }^{T M} 100 \mathrm{bp}$ DNA ladder; MBI Fermentas) containing the following fragments (in base pairs): 1000, 900, 800, 700, 600, 500, 400, 300, and 200.

CTAB extraction method. ${ }^{7}$ The nested PCR for the $T$ gondii SAG1 gene was performed using the conditions and the oligonucleotide primers described earlier. ${ }^{2}$ The PCR products were visualised on $2 \%(\mathrm{wt} / \mathrm{vol})$ agarose gels in TAE (40 mM Tris-Acetate, $1 \mathrm{mM}$ EDTA, pH 8.0) containing ethidium bromide $(5 \mu \mathrm{g} / \mathrm{ml})$. Normally, $15 \mu \mathrm{l}$ of the PCR product was mixed with $3 \mu \mathrm{l}$ gel loading buffer $(0.25 \% \mathrm{wt} / \mathrm{vol}$ bromophenol blue, $0.25 \% \mathrm{wt} / \mathrm{vol}$ xylene cyanol FF, $30 \%$ vol/vol glycerol) and applied on the gel; electrophoresis was performed at 5 volts/cm of gel.

SOUTHERN HYBRIDISATION

Southern hybridisation was carried out using standard methods. ${ }^{8}$ Briefly, any second PCR 
A

1 ACACCGACGG AGAACCACTT CACTCTCAAG TGCCCTAAAA CAGCGCTCAC

51 AgAgCCTCCC ACtCTTGCGT ACTCACCCAA CAGgCAAATC TGCCCAGCGG

101 GTACTACAAG TAGCTGTACA TCAAAGGCTG TAACATTGAG CTCCTTGATT

151 CCTGAAGCAG AAGATAGCTG GTGGACGGGG GATTCTGCTA GTCTCGACAC

201 GGCAGGCATC AAACTCACAG TTCCAATCGA GAAGTTCCCC GTGACAACGC

251 AgACGTTTGT GGTCGgTtGC ATCAAGgGAg ACGACGCACA GAgTtGTATG

301 GTCACGgTGA CAGTACAAGC CAGAGCCTCA tCGgTCGTCA ATAATGTCGC

351 AAGGTGCTCC TACGGTGCAG ACAGCACTCT TGGTCCTGTC AAGTTGTCTG

401 CGgAAGgACC CACTACAATg ACCCTCGTGT gCGGgAAAgA TGgAgTCAAA

451 GTTCCTCAAG ACAACAATCA GTACTGT'TCC GG

B

1 GGTCGAACAC GTCGGGgTGA CCGTCGgGCA CGgGCATCAA TTTTTTGTCG

51 AgGCTCACGG CGTTCTCCCC ATTTCCTCCT CGCGTGTACC TCAGGCTCAC

C

701 AACTGCT

D

1 TGGAGACGGT GTCGTAAGAC ACGGACGCGT GCGCACCGAA GGGAGAAGgC

51 ACCGTGGAAC GGCGTGACGA ACAGGCGATC GAGGCCGTCA AGCTCTACTA

101 CCAGCAGGGC TTGAGCCAGG CCGAGGTTGC CTCCCGTATG GGTCTGTCGC

151 GCCCCACGGT TGCCAAGCTT CTTGCCCACG GCCGCGATCG CGGCTTCGTG

201 ACCATCGAGA TCCATGATCC GCGCGAGGAC GCCTCG

Figure 2 Sequences of the second PCR product from $T$ gondii (A), Mycobacterium tuberculosis (b), Nocardia farcinica (c), and Actinomyces denticola (D). The two PCR primer sequences (20 bases each) are not shown. The GenBank accession numbers for the sequences are: Mycobacterium tuberculosis, AF 133644; Nocardia farcinica, AF133645; and Actinomyces denticola, AF 133646. The Toxoplasma gondii sequence is a part of the SAG1 sequence (GenBank accession number, X14080, M23658). products generated by the putative cross reacting species were separated by electrophoresis on an agarose gel and transferred onto Hybond-N ${ }^{\mathrm{TM}}$ nylon membrane (Amersham Pharmacia-Biotech). Probe preparation, hybridisation, and detection of hybrids was performed as described by the manufacturer of the DIG DNA labelling and detection kit (Boehringer Mannheim). Briefly, the membranes were incubated for six hours at $60^{\circ} \mathrm{C}$ (or at $\left.65^{\circ} \mathrm{C}\right)$ in the hybridisation solution $(5 \times \mathrm{SSC}$, $0.1 \% \mathrm{wt} / \mathrm{vol} \mathrm{N}$-laurylsarcosine, $0.02 \% \mathrm{wt} / \mathrm{vol}$ sodium dodecyl sulphate (SDS), 1\% blocking reagent provided in the kit; $\mathrm{SSC}$ is $0.15 \mathrm{M}$ $\mathrm{NaCl}$ and $0.015 \mathrm{M} \mathrm{Na}_{3}$ citrate), followed by six hours in fresh hybridisation solution containing the probe, which was the 522 bp second PCR product of $T$ gondii labelled using digoxigenin (DIG). Membranes were then washed at the hybridisation temperature twice (five minutes each) in $2 \times$ SSC containing $0.1 \%$ SDS and twice for five minutes each and once for 15 minutes in $0.1 \times \mathrm{SSC}$ containing $0.1 \%$ SDS.

CLONING AND SEQUENCING OF PCR PRODUCTS The PCR products were purified from agarose gels using the QIAquick gel extraction kit (Qiagen) and cloned into the $\mathrm{pGEM}^{\mathrm{R}}-\mathrm{T}$ easy vector as recommended by the supplier (Promega Corporation). Recombinant plasmids were purified using the QIAprep spin miniprep kit (Qiagen) and sequenced at the core sequencing facility in the School of Animal and Microbial Sciences (The University of Reading) using Thermosequenase $^{\mathrm{TM}}$ and an ALF express ${ }^{\mathrm{TM}}$ DNA sequencer as recommended by the supplier (Amersham-Pharmacia Biotech).

\section{Results and discussion}

In the nested PCR assay developed in this laboratory, ${ }^{2}$ use of $T$ gondii DNA as the target generated the expected products (that is, a 914 bp and a $522 \mathrm{bp}$ product following the first and second PCR, respectively) but in the other species examined this was not the case (table 1; fig 1).

With most of the other organisms, the first PCR either did not yield a detectable product or the product was seen as a faint smear. The second PCR with these species generated products which ranged from 100 to $750 \mathrm{bp}$ in length and in some cases only a smear was observed. Our results for Nocardia asteroides (table 1 and fig 1) are different from those reported by McHugh et al, ${ }^{5}$ who showed that the size of the PCR product was the same as that of $T$ gondii.

One explanation for the difference in the size of the PCR products in these two studies is that it may reflect differences in the strains used. In the present study we used a type culture of $N$ asteroides (NCTC 11293), while McHugh et al used a clinical isolate identified as $N$ asteroides. It is also possible that McHugh et al used an $N$ asteroides DNA preparation that may have been contaminated with either $T$ gondii DNA or a $T$ gondii PCR product. In a recent comparison of PCR assays (including ours) for detection of $T$ gondii and the related coccidian parasite Neospora caninum, Ellis ${ }^{9}$ noted that 
false positive results were observed regularly and that they were caused by contamination of reactions with previously amplified DNA. During the course of the present study, similar problems were encountered and strict precautions for avoiding such contamination had to be taken. The results of this study therefore indicate that although PCR products may be generated by organisms other than $T$ gondii, these vary greatly in size and may be differentiated easily on agarose gels.

In order to investigate the nature of the PCR products obtained from cross reacting organisms, we used two approaches. First, we performed Southern blotting and hybridisation to the $522 \mathrm{bp}$ PCR product from $T$ gondii so as to increase the sensitivity of detection and to obtain insight into the extent of similarity between the PCR products of the different species. The results (table 1) showed that at the stringent hybridisation temperature of $65^{\circ} \mathrm{C},{ }^{2}$ routinely used for our clinical investigations, only the $T$ gondii PCR product hybridised; however, at conditions of lower stringency (at a hybridisation temperature of $60^{\circ} \mathrm{C}$ ) all the PCR products hybridised. Therefore the results indicate that there is little sequence similarity between the PCR products of $T$ gondii and those of the cross reacting species; consequently, if hybridisation at stringent conditions is used for diagnostic purposes, false positives are not evident.

The second approach used to investigate the nature of the PCR products from the cross reacting organisms was cloning and nucleotide sequence determination of the second PCR products obtained from Mycobacterium tuberculosis, Actinomyces denticola, and Nocardia farcinica. The DNA sequences obtained from these PCR products and that from $T$ gondii are shown in fig 2. Comparisons of these DNA sequences confirmed that, at the nucleotide level, there was no significant similarity between the various PCR products and the nucleotide sequence of the SAG1 gene of T gondii. ${ }^{10}$
In conclusion, therefore, although the SAG1 based nested PCR assay generates PCR products from DNA of some other species under certain conditions, it remains effective for the clinical diagnosis of toxoplasmosis if carried out under the stringent conditions described earlier. ${ }^{2}$ In any case, the results may be confirmed by performing hybridisation of the PCR products with the toxoplasma probe to substantiate the identity of the PCR products obtained. However, it is important to ensure that adequate measures are taken to avoid any contamination with $T$ gondii DNA or PCR products, or both, as such contamination will inevitably result in false positive diagnoses. Our findings emphasise the need for strict adherence to published protocols when using molecular methods for clinical diagnosis.

We are grateful to the Felix Foundation for financial support in the form of a Felix Scholarship (MB). The original development of the SAG1 (p30) gene PCR assay was supported by the Medical Research Council.

1 Burg JL, Grover CM, Ponletty P, et al. Direct and sensitive detection of a pathogenic protozoan, Toxoplasma gondii, 1989;27:1787-92.

2 Savva D, Morris JC, Johnson JD, et al. Polymerase chain reaction for detection of Toxoplasma gondii. $\mathcal{f}$ Med Microbiol 1990;32:25-31.

3 Weiss LM, Uden SA, Salgo M, et al. Sensitive and specific detection of toxoplasma DNA in an experimental murine model: use of Toxoplasma gondii-specific cDNA and the polymerase chain reaction. F Infect Dis 1991;163:180-6.

4 Johnson JD, Butcher PD, Savva D, et al. Application of the polymerase chain reaction to the diagnosis of human toxoplasmosis. F Infect 1993;26:147-58.

5 McHugh TD, Ramsay AR, James EA, et al. Pitfalls of PCR: misdiagnosis of cerebral nocardia infection. Lancet 1995; 346:1436.

6 Holliman RE, Patel B, Johnson JD, et al. Pitfalls of PCR: misdiagnosis of cerebral nocardia infection. Lancet 1996; 347:335-6.

7 Ausubel FM, Brent R, Kingston RE, et al. Current protocols in molecular biology. New York: John Wiley and Sons, 1994.

8 Sambrook J, Fritsch EF, Maniatis T. Molecular cloning. A laboratory manual. 2nd ed. Cold Spring Harbor, New York: Cold Spring Harbor Laboratory Press, 1989.

9 Ellis JT. Polymerase chain reaction approaches for the detection of Neospora caninum and Toxoplasma gondii. detection of Neospora caninum
Int $\mathcal{F}$ Parasitol 1998;28:1053-60.

10 Burg JL, Perelman D, Kasper LH, et al. Molecular analysis of the gene encoding the major surface antigen of Toxoplasma gondii. F Immunol 1988,141:3584-91. 